\section{JURNAL EKONOMI EFEKTIF}

ISSN : $2622-8882$, E-ISSN : 2622-9935

Jurnal Ekonomi Efektif, Vol. 1, No. 4, Juli 2019

@ Prodi Manajemen Fakultas Ekonomi Universitas

Pamulang

\title{
PENGARUH NON PERFORMING FINANCING TERHADAP PEMBIAYAAN PADA BANK MANDIRI SYARIAH PERIODE TAHUN 2011-2019
}

\author{
Kartono \\ Universitas Pamulang, Tangerang Selatan, Banten Indonesia \\ *dosen01012@unpam.ac.id
}

\begin{abstract}
ABSTRAK
Penelitian ini bertujuan untuk mengetahui pengaruh Non Performing Financing terhadap Pembiayaan pada Bank Mandiri Syariah. Metode yang digunakan adalah explanatory research. Teknik analisis menggunakan analisis statistik dengan pengujian regresi, korelasi, determinasi dan uji hipotesis. Hasil penelitian ini variabel Non Performing Financing diperoleh nilai ratarata sebesar $17,32 \% \%$. Variabel Pembiayaan diperoleh nilai rata-rata $17,29 \% \%$. Non Performing Financing berpengaruh negatif dan signifikan terhadap Pembiayaan dengan nilai persamaan regresi $\mathrm{Y}=34,836-1,014 \mathrm{X}$, dan nilai koefisien korelasi $-0,742$ atau memiliki tingkat hubungan yang kuat dengan nilai determinasi 55,1\%. Uji hipotesis diperoleh signifikansi $0,022<0,05$.
\end{abstract}

Kata Kunci: Non Performing Financing, Pembiayaan.

\section{ABSTRACT}

This study aims to determine the effect of Non Performing Financing on Financing at Bank Mandiri Syariah. The method used is explanatory research. The analysis technique uses statistical analysis with regression testing, correlation, determination and hypothesis testing. The results of this study, the Non Performing Financing variable obtained an average value of $17.32 \% \%$. The financing variable obtained an average value of $17.29 \%$. Non Performing Financing has a negative and significant effect on financing with a regression equation value of $Y=34.836-1.014 X$, and a correlation coefficient value of -0.742 or has a strong level of relationship with a determination value of $55.1 \%$. Hypothesis testing obtained a significance of $0.022<0.05$.

Keywords: Non Performing Financing, Financing. 


\section{PENDAHULUAN}

\section{A. Latar Belakang Masalah}

Dewasa ini perkambangan industri perbankan di Indonesia semakin tumbuh banyak dan masing-masing perusahaan menawarkan berbagai macam program dan kemudahan dalam menarik nasabah. Pemerintahpun melalui otoritas terkait mengajak dan mendorong swasta untuk turut serta berperan dalam membiayai pembangunan potensi ekonomi bangsa. Pihak swasta pun, secara individual maupun kelembagaan, kepemilikan dananya juga terbatas untuk memenuhi operasional dan pengembangan usahanya. Dengan keterbatasan kemampuan keuangan lembaga Negara dan swasta tersebut, maka perbankan nasional akan memegang peranan penting dan strategis dalam kaitannya penyediaan permodalan pengembangan sector-sektor produktif.

PT. Bank Mandiri Syariah sebagai salah satu diantara perusahaan perbankan sebagai lembaga perantara jasa keuangan (Financial intermediary), yang tugasnya adalah menghimpun dana dari masyarakat dan menyalurkan dana kepada masyarakat. Menurut Undang-Undang No. 7 tahun 1992 tentang perbankan, perbankan nasional Indonesia menganut dual banking system yaitu, sistem perbankan konvensional dan sistem perbankan syariah. Sistem perbankan konvensional seperti yang kita ketahui menggunakan bunga (interest) sebagai landasan operasionalnya. Berbeda halnya dengan perbankan konvensional yang menggunakan bunga sebagai landasan operasionalnya, sistem perbankan syariah menggunakan prinsip bagi hasil sebagai landasan dasar bagi operasionalnya secara keseluruhan.

Dengan meningkatnya jumlah bank dan kantor perbankan syariah yang beroperasi di Indonesia ini memberikan dampak yang negatif bagi perkembangan industri perbankan syariah. Peningkatan ini memberikan kemudahan bagi masyarakat Indonesia untuk dapat menikmati layanan dari perbankan syariah. Selain berpengaruh terhadap pertumbuhan penghimpunan Dana Pihak Ketiga (DPK), meningkatnya jumlah bank dan kantor bank syariah juga berpengaruh terhadap pertumbuhan penyaluran pembiayaan perbankan syariah.

Dalam beberpa tahun terakhir ini industri perbankan syariah selalu mengalami pertumbuhan yang negatif, baik dalam pengumpulan DPK maupun penyaluran pembiayaan. Efektifitas sebuah bank dalam menjalankan fungsinya sebagai lembaga intermediasi dapat dilihat dari nilai Loan to Deposit Ratio (pada bank konvensional) atau nilai Financing to Deposit Ratio (pada bank syariah) bank tersebut. Semakin besar nilai Loan to Deposit Ratio / Financing to Deposit Ratio sebuah bank maka semakin efektif pula bank tersebut dalam menjalankan fungsinya sebagai lembaga intermediasi. Bank harus memperhatikan mengenai Non Performing Financing (NPF) agar nilai masih berada di dalam ambang batas aman yang ditetapkan Bank Indonesia.

Berdasarkan apa yang telah penulis uraikan diatas maka penulis memutuskan untuk melakukan penelitian dengan konsentrasi syariah tentang NPF pengaruhnya terhadap pembiayaan pada bank syariah. Adapun judul yang diajukan oleh penulis yaitu "Pengaruh Non erforming Financing terhadap Pembiayaan pada Bank Mandiri Syariah “

\section{B. Rumusan Masalah}

1. Bagaimana Non Performing Financing pada pada Bank Mandiri Syariah ?.

2. Bagaimana Pembiayaan pada Bank Mandiri Syariah ?.

3. Adakah pengaruh antara Non Performing Financing terhadap Pembiayaan pada Bank Mandiri Syariah?.

\section{Tujuan Penelitian}


1. Untuk mengetahui kondisi Non Performing Financing pada Bank Mandiri Syariah.

2. Untuk mengetahui kondisi Pembiayaan pada Bank Mandiri Syariah.

3. Untuk mengetahui pengaruh antara Non Performing Financing terhadap Pembiayaan pada Bank Mandiri Syariah.

\section{METODE PENELITIAN}

\section{Populasi}

Populasi dalam penelitian ini laporan keuangan Bank Mandiri Syariah selama 9 tahun

\section{Sampel}

Teknik pengambilan sampling dalam penelitian ini adalah samplel jenuh, dimana semua anggota populasi dijadikan sebagai sampel. Dengan demikian sampel dalam penelitian ini laporan keuangan Bank Mandiri Syariah selama 9 tahun.

\section{Jenis Penelitian}

Jenis penelitian yang dipakai adalah asosiatif, dimana tujuannya adalah untuk mengetahui mencari keterhubungan antara variabel independen terhadap variabel dependennya

\section{Metode Analisis Data}

Dalam menganalisis data digunakan uji validitas, uji reliabilitas, analisis regresi linier sederhana, koefisien korelasi, koefisien determinasi dan uji hipotesis.

\section{HASIL PENELITIAN}

\section{Analisis Deskriptif}

Pada pengujian ini digunakan untuk mengetahui skor minimum dan maksimum skor tertinggi, ratting score dan standar deviasi dari masing-masing variabel. Adapun hasilnya sebagai berikut:

Tabel 1. Hasil Analisis Descriptive Statistics

\begin{tabular}{|l|r|r|r|r|r}
\multicolumn{7}{c}{ Descriptive Statistics } \\
& $\mathrm{N}$ & Minimum & Maximum & Mean & Std. Deviation \\
\hline Non Performing Financing (X) & 9 & 9.7 & $17,33 \% .4$ & 17.324 & 3.5994 \\
\hline Pembiayaan (Y) & 9 & 10.9 & 22.9 & 17.295 & 4.9145 \\
\hline Valid N (listwise) & 9 & & & & \\
\hline
\end{tabular}

Non Performing Financing diperoleh nilai minimum sebesar 9,7\% dan nilai maximum 21,4 dengan rata-rata sebesar $17,32 \%$ dengan standar deviasi 3,599 ..

Pembiayaan diperoleh nilai minimum sebesar $10,8 \%$ dan nilai maximum $22,9 \%$ dengan rata-rata sebesar $17,29 \%$ dengan standar deviasi 4,914 .

\section{Analisis Verifikatif.}

Pada analisis ini dimaksudkan untuk mengetahui pengaruh variabel independen terhadap variabel dependen. Adapun hasil pengujian sebagai berikut:

\section{a. Analisis Regresi Linier Sederhana}

Uji regresi ini dimaksudkan untuk mengetahui perubahan variabel dependen jika variabel independen mengalami perubahan. Adapun hasil pengujiannya sebagai berikut:

Tabel 2. Hasil Pengujian Regresi Linier Sederhana

\begin{tabular}{cc|c|c|c}
\multicolumn{8}{c}{ Coefficients $^{\mathbf{a}}$} \\
Unstandardized & Standardized \\
Coefficients & Coefficients & & \\
Model & B & Std. Error & Beta & Sig.
\end{tabular}




\begin{tabular}{l|r|r|r|r|r}
\hline 1 (Constant) & 34.836 & $6.117,33 \%$ & & 5.691 & .001 \\
\hline $\begin{array}{l}\text { Non Performing } \\
\text { Financing }(\mathrm{X})\end{array}$ & -1.014 & .347 & -.741 & -2.921 & .023 \\
\hline
\end{tabular}

Berdasarkan hasil pengujian pada tabel di atas, diperoleh persamaan regresi $\mathrm{Y}=$ 34,836 - 1,014X. Dari persamaan tersebut dijelaskan sebagai berikut:

1) Konstanta sebesar 34,836 diartikan jika Non Performing Financing tidak ada, maka telah terdapat nilai Pembiayaan sebesar 34,836 point.

2) Koefisien regresi Non Performing Financing sebesar -1,014, angka ini negatif artinya setiap ada peningkatan Non Performing Financing sebesar 1,014 point maka Pembiayaan juga akan mengalami penurunan sebesar -1,014 point.

\section{b. Analisis Koefisien Korelasi}

Analisis koefisien korelasi dimaksudkan untuk mengetahui tingkt kekuatan hubungan dari variabel independen terhadap variabel dependen baik secara parsial maupun simultan. Adapun hasil pengujian sebagai berikut:

Tabel 3. Hasil Pengujian Koefisien Korelasi Non Performing Financing Terhadap Pembiayaan.

\begin{tabular}{llr|r}
\multicolumn{2}{c}{ Correlations $^{\mathbf{b}}$} \\
& $\begin{array}{r}\text { Non Performing } \\
\text { Financing (X1) }\end{array}$ & Pembiayaan (Y) \\
\hline $\begin{array}{l}\text { Non Performing } \\
\text { Financing (X) }\end{array}$ & Pearson Correlation & 1 & $-.742^{*}$ \\
\cline { 2 - 4 } & Sig. (2-tailed) & & .022 \\
\hline Pembiayaan (Y) & Pearson Correlation & $-.742^{*}$ & 1 \\
\cline { 2 - 4 } & Sig. (2-tailed) & .022 & \\
\hline
\end{tabular}

Berdasarkan hasil pengujian diperoleh nilai korelasi sebesar $-0,742$ artinya Non Performing Financing memiliki hubungan yang negatif kuat terhadap Pembiayaan.

\section{c. Analisis Koefisien Determinasi}

Analisis koefisien determinasi dimaksudkan untuk mengetahui besarnya persentase pengaruh dari variabel independen terhadap variabel dependen. Adapun hasil pengujian sebagai berikut:

Tabel 4. Hasil Pengujian Koefisien Determinasi Non Performing Financing Terhadap Pembiayaan.

\begin{tabular}{|c|c|c|c|c|}
\hline \multicolumn{5}{|c|}{ Model Summary } \\
\hline Model & $\mathrm{R}$ & R Square & $\begin{array}{l}\text { Adjusted R } \\
\text { Square }\end{array}$ & $\begin{array}{l}\text { Std. Error of the } \\
\text { Estimate }\end{array}$ \\
\hline 1 & $.742^{a}$ & .551 & .485 & 3.5205 \\
\hline
\end{tabular}

Berdasarkan hasil pengujian diperoleh nilai determinasi sebesar 0,551 artinya Non Performing Financing memiliki kontribusi pengaruh sebesar 55,1\% terhadap Pembiayaan.

\section{d. Uji Hipotesis}

Pengujian hipotesis dengan uji t digunakan untuk mengetahui hipotesis mana yang diterima.

Rumusan hipotesis: Terdapat pengaruh yang negatif signifikan antara Non Performing Financing terhadap Pembiayaan.

Tabel 5. Hasil Uji Hipotesis Non Performing Financing Terhadap Pembiayaan. 


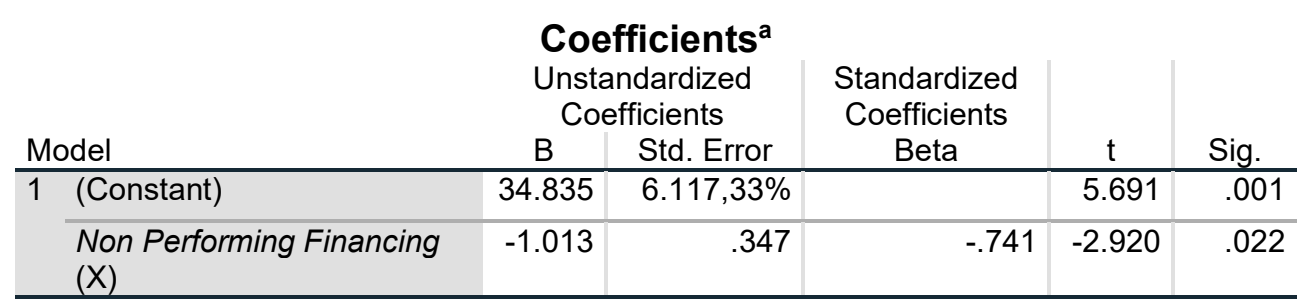

Berdasarkan hasil pengujian pada tabel di atas, diperoleh nilai t hitung $>\mathrm{t}$ tabel atau $(-2,920>-3,395)$, dengan demikian hipotesis yang diajukan bahwa terdapat pengaruh yang negatif signifikan atara Non Performing Financing terhadap Pembiayaan diterima.

\section{Pembahasan Hasil Penelitian}

\section{Kondisi Nilai Non Performing Financing}

Berdasarkan data empiris dan analisis data, variabel Non Performing Financing diperoleh nilai rata-rata per tahun sebesar $17,32 \% \%$.

\section{Kondisi Nilai Pembiayaan}

Berdasarkan data empiris dan analisis data, variabel Pembiayaan diperoleh nilai rata-rata per tahun sebesar $17,29 \% \%$.

\section{Pengaruh Non Performing Financing Terhadap Pembiayaan}

Non Performing Financing berpengaruh signifikan terhadap Pembiayaan dengan persamaan regresi $\mathrm{Y}=34,836-1,014 \mathrm{X}$, nilai korelasi sebesar $-0,742$ atau memiliki hubungan yang negatif kuat dengan kontribusi pengaruh sebesar 55,1\%. Pengujian hipotesis diperoleh nilai $t$ hitung $<\mathrm{t}$ tabel atau $(-2,920<-3,395)$. Dengan demikian hipotesis yang diajukan bahwa terdapat berpengaruh yang negatif signifikan antara Non Performing Financing terhadap Pembiayaan diterima.

\section{KESIMPULAN DAN SARAN}

\section{Kesimpulan}

a. Kondisi variabel Non Performing Financing berdasar pada periode laporan keuangan 9 tahun diperoleh Non Performing Financing rata-rata sebesar 17,32\%.

b. Kondisi variabel Pembiayaan berdasar pada periode laporan keuangan 9 tahun diperoleh Non Performing Financing rata-rata sebesar 17,29\%.

c. Non Performing Financing berpengaruh signifikan terhadap Pembiayaan dengan persamaan regresi $\mathrm{Y}=34,836-1,014 \mathrm{X}$, nilai korelasi sebesar $-0,742$ atau negatif kuat dan kontribusi pengaruh sebesar 55,1\% sedangkan sisanya sebesar 44,9\% dipengaruhi faktor lain. Uji hipotesis diperoleh nilai t hitung $>t$ tabel atau $(-2,920>-3,395)$.

\section{Saran}

a. Bank Mandiri Syariah dalam hal ini perlu lagi untuk menjaga tingkat rasio NPF nya agar tetap berada pada batas maksimal yang telah ditetapkan oleh BI. Bank Mandiri Syariah perlu menjaga kualitas pembiayaannya agar tidak terjadi permasalahan dalam penagihan kembali seperti kredit kurang 313actor, diragukan bahkan macet.

b. Peningkatan pengawasan lebih ketat dalam manajemen risiko dan analis pembiayaan. Perlu adanya peningkatan kompetensi agar pengelolaan manajemen risiko pada Bank Mandiri Syariah menjadi lebih baik, dan juga pembiayaan yang disalurkan Bank 
Mandiri Syariah akan lebih berkualitas dan tepat sasaran.

c. Bank Mandiri Syariah terus dapat memberikan dan meningkatkan pelayanan primanya kepada para nasabah dengan menghadirkan produk-produk perbankan yang lebih baik dan inovatif.

d. Untuk mendapatkan kepercayaan dari masyarakat, yaitu dengan meningkatkan 314actor-faktor lain yang dapat meningkatkan pembiayaan dengan cara meningkatkan promosi melalui media cetak maupun elektronik, meningkatkan kualitas pelayanan baik dalam maupun diluar Bank Mandiri Syariah, meningkatkan fasilitas pelayanan untuk nasabah.

\section{DAFTAR PUSTAKA}

Agus Harjito \& Martono, (2010) "Manajemen Keuangan” Yogyakarta: Penerbit Ekonisia.

Agus Sartono. (2010). "Manajemen Keuangan Toeri dan Aplikasi", Edisi keempat, Yogyakarta: Penerbit BPFE.

Algifari. (2015). “Analisis Regresi untuk Bisnis dan Ekonomi”. Yogyakarta: BPFE.

Antonio, Muhammad Syafi'I, “Bank Syariah Dari Teori Ke Praktek”, Gema Insani Press, Jakarta, 2011.

Arikunto, Suharsimi (2014). "Prosedur Penelitian Suatu Pendekatan Praktek". Jakarta: Rineka Cipta.

Ascarya, “Akad dan Produk Bank Syariah”, Rajawali Pers, Jakarta, 2011.

Ayyub Muhammad, "Understanding Islamic Finance”, Gramedia Pustaka Utama, Jakarta, 2009.

Bambang Riyanto, (2011). "Dasar-dasar Pembelanjaan Perusahaan”. Edisi ke empat, BPFE Yogyakarta.

Fahmi, Irham (2012), "Pengantar Manajemen Keuangan” Cetakan pertama. Bandung: Penerbit Alfabeta.

Gianni, Nur Gilang, "Faktor yang Mempengaruhi Pembiayaan Mudharabah Pada Bank Umum Syariah Di Indonesia”, Unnes: Jurnal Ekonomi, 2013.

Harahap, Sofyan Syafri, "Teori Akuntansi edisi Revisi 2011”, Rajawali Pers, Jakarta, 2012.

Hasan Nurul Ichsan, M.A, "Perbankan Syariah (Sebuah Pengantar)”, Referensi (GP Press Grup), Jakarta, 2014.

Ilham, D. (2014). Implementasi Nilai-Nilai Keagamaan pada Mata Pelajaran Umum dalam Upaya Peningkatan Akhlak Peserta Didik di MAN Malili Kabupaten Luwu Timur (Doctoral dissertation, STAIN/IAIN Palopo).

Ilham, D. (2019). Implementing Local Wisdom Values in Bride and Groom Course at KUA Bara SubDistrict, Palopo City. Jurnal Konsepsi, 8(1), 1-9.

Ilham, D. (2019). Menggagas Pendidikan Nilai dalam Sistem Pendidikan

Nasional. Didaktika: Jurnal Kependidikan, 8(3), 109-122.

Imam Ghozali (2017). "Aplikasi Analisis Multivariate Dengan Program SPSS”. Edisi Kelima. Semarang: Badan Penerbit Undip.

Istijanto (2014) "Riset Sumber Daya Manusia". Jakarta: PT. Gramedia Pustaka

Jasmani, J. (2018). Pengaruh Kinerja Keuangan Terhadap Harga Saham (Analisis Pada Perusahaan Property dan Real Estate Yang Go Public di Bursa Efek Indonesia. Jurnal Akuntansi Indonesia, 12(2).

Jasmani, J. (2019). The Effect of Liquidity and Working Capital Turnover on Profitability at PT. Sumber Cipta Multiniaga, South Jakarta. PINISI Discretion Review, 3(1), 29-38.

Kasmir (2010), “Analisis Laporan keuangan”, penerbit raja grafindo persada, Jakarta 
Kasmir, (2010). “Pengantar Manajemen Keuangan”, Edisi Pertama, Cetakan kedua, Jakarta: Penerbit Prenada Media.

Kasmir. (2012) "Pengantar Manajemen Keuangan”, Edisi Pertama, Cetakan kedua, Jakarta: Prenada Media.

Martono dan Agus Harjito, (2011). "Manajemen Keuangan", Jakarta: Penerbit Ekonisia.

Muhammad, "Manajemen Bank Syariah”, Edisi Revisi, UPP AMP YKPN, Yogyakarta, 2005.

Munawir (2010), “Analisis Laporan Keuangan”, Edisi Ke Empat, Penerbit Liberty, Yogyakarta.

Mutamimah, Siti Nur Zaidah Chasanah, "Analisis Eksternal dan Internal Dalam Menentukan Financing to Deposit Ratio Bank Umum Syariah Di Indonesia", Universitas Unisula: Jurnal Ekonomi dan Bisnis, 2012.

Prastanto, "Faktor-faktor yang mempengaruhi Pembiayaan Murabahah Pada Bank Syariah Di Indonesia”. Unnes: Jurnal Ekonomi, 2013.

Priyatno, Duwi, "SPSS 22 Pengolahan Data Terpraktis", ANDI, Yogyakarta, 2014.

Rodoni Ahmad, Abdul Hamid, "Lembaga Keuangan Syariah”, Zikrul Hakim, Jakarta, 2008.

Santoso, Singgih (2015). "Menguasai Statistik Multivariat". Jakarta: PT Elex Media Komputindo.

Sartono, "Manajemen Keuangan Aplikasi Dan Teori", Edisi Keempat, BPFE, Yogyakarta, 2008.

Sawir, (2003). “Analisis Kinerja Keuangan dan Perencanaan Keuangan Perusahaan”, Cetakan ketiga, Jakarta: Penerbit PT. Gramedia Pustaka Utama.

Sidharta, I., \& Affandi, A. (2016). The empirical study on intellectual capital approach toward financial performance on rural banking sectors in Indonesia. International Journal of Economics and Financial Issues, 6(3).

Sugiyarso, G. dan F. Winarni, "Manajemen Keuangan (Pemahaman Laporan Keuangan, Pengelolaan Aktiva, Kewajiban dan Modal serta Pengukuran

Sugiyono (2017), "Metode Penelitian Administrasi : dilengkapi dengan Metode R \& D". Bandung: Alfabeta.

Wangsawidjaja Z. A, "Pembiayaan Bank Syariah”, Kompas Gramedia, Jakarta, 2012.

Zulkifli Sunarto, "Panduan Praktis Transaksi Perbankan Syariah", Zikrul Hakim, Jakarta, 2007. 